\title{
Discovery of new small molecules inhibiting 67 kDa laminin receptor interaction with laminin and cancer cell invasion
}

\author{
Ada Pesapane ${ }^{1}$, Carmen Di Giovanni ${ }^{2}$, Francesca Wanda Rossi ${ }^{1}$, Daniela Alfano ${ }^{3}$, \\ Luigi Formisano ${ }^{4}$, Pia Ragno ${ }^{5}$, Carmine Selleri ${ }^{6}$, Nunzia Montuori ${ }^{1}$, Antonio \\ Lavecchia $^{2}$ \\ ${ }^{1}$ Department of Translational Medical Sciences, University of Naples Federico II, Naples, Italy \\ ${ }^{2}$ Department of Pharmacy, Drug Discovery Laboratory, University of Naples Federico II, Naples, Italy \\ ${ }^{3}$ Institute of Genetics and Biophysics Adriano Buzzati-Traverso, Consiglio Nazionale delle Ricerche (CNR), Naples, Italy \\ ${ }^{4}$ Department of Science and Technology, University of Sannio, Benevento, Italy \\ ${ }^{5}$ Department of Chemistry, University of Salerno, Salerno, Italy \\ ${ }^{6}$ Department of Medicine and Surgery, University of Salerno, Salerno, Italy
}

Correspondence to:

Nunzia Montuori, e-mail: nmontuor@unina.it

Keywords: laminin receptor, small molecules, laminin, cell adhesion

Received: March 06, 2015

Accepted: May 18, 2015

Published: May 29, 2015

\section{ABSTRACT}

The $67 \mathrm{kDa}$ laminin receptor (67LR) is a non-integrin receptor for laminin (LM) that derives from a $37 \mathrm{kDa}$ precursor (37LRP). 67LR expression is increased in neoplastic cells and correlates with an enhanced invasive and metastatic potential.

We used structure-based virtual screening (SB-VS) to search for 67LR inhibitory small molecules, by focusing on a 37 LRP sequence, the peptide $G$, able to specifically bind LM. Forty-six compounds were identified and tested on HEK-293 cells transfected with 37LRP/67LR (LR-293 cells). One compound, NSC47924, selectively inhibited LR293 cell adhesion to $L M$ with $I_{50}$ and $K_{i}$ values of 19.35 and $2.45 \mu \mathrm{mol} / \mathrm{L}$.

NSC47924 engaged residues $\mathrm{W} 176$ and $\mathrm{L173}$ of peptide G, critical for specific LM binding. Indeed, NSC47924 inhibited in vitro binding of recombinant 37LRP to both LM and its YIGSR fragment. NSC47924 also impaired LR-293 cell migration to LM and cell invasion.

A subsequent hierarchical similarity search with NSC47924 led to the identification of additional four compounds inhibiting LR-293 cell binding to LM:

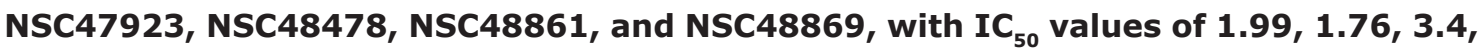
and $4.0 \mu \mathrm{mol} / \mathrm{L}$, respectively, and able to block in vitro cancer cell invasion.

These compounds are promising scaffolds for future drug design and discovery efforts in cancer progression.

\section{INTRODUCTION}

The $67 \mathrm{kDa}$ laminin receptor (67LR) was originally identified as a non-integrin cell surface receptor for LM [1], the major component of basement membranes [2]. Interactions between 67LR and LM play a major role in mediating cell adhesion [3], migration [4], proliferation and survival [5].

67LR derives from homo- [6] or hetero- [7] dimerization of a $37 \mathrm{kDa}$ cytosolic precursor (37LRP) [8], most probably by fatty acid acylation. 37LRP is mostly found in the cytosol [9] and nucleus [10] where it is involved in translational processes and maintenance of nuclear structures, respectively. 67LR is localized at the cell surface [11] and it not only serves as a receptor for LM but also acts as a receptor for elastin [12], carbohydrates [13] and the cellular prion protein [14].

67LR binds LM through different binding domains: a palindromic sequence known as peptide $\mathrm{G}[11,15]$, a predicted helical domain corresponding to 37LRP residues 205-229, and TEDWS-containing C-terminal repeats 
[13]. 67LR is co-expressed and can physically interact with the $\alpha_{6}$ integrin chain [16]. LM conformation changes upon binding 67LR, thus interacting more efficiently with integrins [17] and becoming more sensitive to the action of proteolytic enzymes [18], with the release of motility fragments [19].

67LR expression is increased in neoplastic cells as compared to their normal counterparts and directly correlates with an enhanced invasive and metastatic potential [20], mediated by high-affinity interactions between 67LR and LM [21].

Cell adhesion to the basement membrane allows tumor cells to secrete proteolytic enzymes, i.e. type IV collagenase, able to degrade components of the extracellular matrix (ECM). Degradation of these components, in turn, induces invasion of the basement membrane, enabling cancerous cells to migrate and form metastasis. Thus, 67LR overexpression is a molecular marker of aggressiveness in cancers of many tissues, including breast, lung, ovary, prostate and also in leukaemia and lymphomas [22-24].

The correlation between 37LRP/67LR levels and tumor aggressiveness recommends the receptor as a new promising target for cancer treatment. This is supported by in vivo studies showing that high 67LR levels result in tumor growth and proliferation [25, 26]. Knockdown of 37LRP using siRNAs resulted in decreased cell survival suggesting that $37 \mathrm{LRP} / 67 \mathrm{LR}$ could also enhance cell viability by blocking apoptosis [27]. Indeed, we recently demonstrated the structural and functional association of 67LR with the antiapoptotic protein PED/PEA-15 [28]. Furthermore, recent findings demonstrated that an anti-37LRP/67LR specific antibody significantly impeded angiogenesis, thus suggesting the receptor might also be involved in tumor angiogenesis [29].
However, an anti-37LRP/67LR specific antibody decreased the invasive potential of human fibrosarcoma cells [30], thus indicating that 67LR plays a critical role in tumor invasion and metastasis through its interaction with LM.

The $2.15 \AA$ resolution crystal structure of the partial domain of human 67LR [31] provides an excellent platform for rational drug design. For these reasons, we used structure-based virtual screening (SB-VS) [32] of the National Cancer Institute (NCI) Diversity Set with nonredundant structures to identify small molecules targeting 67LR and able to disrupt cell binding to LM. SBVS, which uses computer-based methods for identifying promising compounds to bind to a target molecule of known structure, is a widely used method that has been shown to be successful in a variety of studies, although it also has many shortcomings [33].

Here, we describe the successful outcome of this search and the initial biological evaluation of the most promising compounds from this effort.

\section{RESULTS}

\section{Identification of a druggable pocket within the human 67LR structure}

Recently, the structure of the N-terminal of 37LRP (residues 1-220) has been solved by X-ray crystallography [31] with resolution of $2.15 \AA$ (Protein Data Bank ID code $3 \mathrm{BCH}$ ) (Figure 1A). 37LRP was shown to have a globular structure comprising five $\alpha$-helical and seven $\beta$-folded regions. This structure shows a high degree of similarity to ribosomal protein SA or $\mathrm{p} 40$ from prokaryotes and lower eukaryotes [9, 34]. Since 37LRP crystal structure begins at residue 9 (Q9; single-letter amino-acid code) and finishes at residue 205 (R205) (both indicated on the Figure 1A), it lacks almost all the $\mathrm{C}$-terminal domain, not present in the
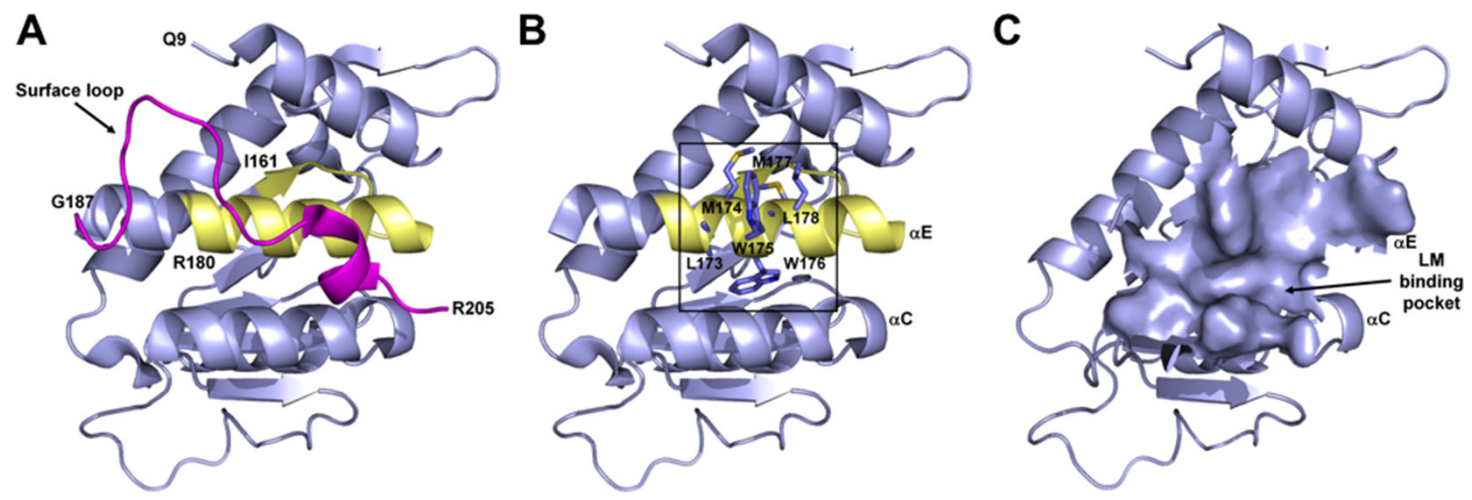

Figure 1: Structure of human 37LRP. A. Structure of human 37LRP represented as a slate blue cartoon. The structure begins at residue Q9 and finishes at residue R205, lacking almost all the C-terminal LM-binding site, which starts at residue R205. Peptide G (residues 161-180) is shown in yellow. The surface loop (residues 187-205), which covers the palindromic sequence of peptide G, is shown in magenta. B. Structure of human 37LRP lacking of the surface loop. The palindromic sequence of peptide G (LMWWML) is circled in black. C. The $2265 \AA^{2}$ putative LM binding pocket lying between $\alpha \mathrm{C}$ and $\alpha \mathrm{E}$ helices of 37LRP. Figures were produced using the coordinates from Protein Data Bank file 3BCH (35) and PyMOL (www.pymol.org). 
prokaryotic and lower eukaryotic ribosomal proteins [35], which starts at residue 205.

Among the different 67LR binding sites for LM, we focused on peptide $G$ for the abundant clinical and experimental data indicating its critical role in tumor invasion and metastasis $[11,15,17-21]$. Peptide G (residues 161-180, IPCNNKGAHSVGLMWWMLAR) binds $\mathrm{LM}$ with high affinity $\left(\mathrm{K}_{\mathrm{d}}=51.8 \mathrm{nM}\right)[11,15$, 17]. Moreover, evolutionary studies suggested that the acquisition of the LM-binding capability of 67LR is linked to the palindromic sequence LMWWML contained within the peptide $G$ [35]. Peptide $G$ forms part of a $\beta$-strand (residues 160-162), an $\alpha$-helix (residues 168-186) and a surface loop (residues 187-205), much of which is buried in the interior of the molecule. The only portion of it that is solvent-accessible includes residues 165-169.

The crystal structure of 37LRP reveals that the surface loop completely covers the palindromic sequence of peptide $\mathrm{G}$, making it inaccessible to binding of LM (Figure 1A); thus, it has been postulated that considerable conformational changes are required to enable LM binding. Indeed, we found that loop 188-197 in the $\mathrm{C}$-terminal region is highly flexible and undergoes a major change resulting in a conformational switch that partially solvent exposes the final part of peptide G [36].

Thus, with the aim of exposing the palindromic sequence (Figure 1B) involving protein-LM interactions, we truncated the surface loop of 37LRP (residues 187-205) from the available crystallographic structure. One cavity was intercepted in close proximity of the palindromic residue W176. This groove lies between two $\alpha$ helices $(\alpha \mathrm{C}$ and $\alpha \mathrm{E})$ and covers a surface area of $2265 \AA^{2}$ (Figure 1C). The site is predominantly hydrophobic in nature (L173, M174, M177, L178, A86, G172, A93, A179, G172, A168, F90, W175, W176) with a few H-bond donors and acceptors. This putative cavity, that we hypothesize to be involved in LM binding, was chosen for in silico targeting in a SB-VS approach.

\section{Identification by SB-VS of small molecules directed to the peptide $G$ cavity of $67 \mathrm{LR}$}

An in silico screening approach was undertaken to identify compounds from the NCI Diversity library with a potential to bind at the putative cavity on the peptide $\mathrm{G}$ of 67LR and hamper LM binding. 3D structures of compounds from the NCI's chemical libraries were downloaded from the NCI Developmental Therapeutics Program web site (http://dtp.nci.nih.gov/branches/dscb/repo_open. html/) and processed with LigPrep software to produce 2, 560 3D structures for the Diversity Set. Docking calculations were carried out by using the Glide software [37]. Then, Glide SP docked each chemical structure into the 67LR/LM binding site retaining the $10 \%$ of the top-scoring ligands. The resulting 188 compounds were then redocked and scored with Glide XP in order to estimate binding affinity and rank the ligands. The 188 ranked compounds were analyzed by visual inspection because it has broadly demonstrated that docking scoring functions are often more successful at predicting a binding pose than the actual binding affinity [38]. Finally, compounds were checked for readily sample availability from the compound provider, and 46 structurally diverse compounds (compounds 1-46 in Chart 1 of Supplementary Material: SB-VS selected small molecules directed to the peptide $\mathrm{G}$ cavity of $67 \mathrm{LR}$ ) were requested and tested in a cell-based assay.

\section{Human 37LRP cDNA transfection in HEK-293 cells results in cell surface expression of the active receptor and increased cell adhesion to $L M$}

As a model to mimic the effects of 67LR overexpression in cancer cells, HEK-293 cells were stably transfected with a human 37LRP cDNA fused at the C-terminal with a tag derived from phage T7 and a polyhistidine stretch (LR-293 cells) or with an empty vector (V-293 cells).

37LRP expression was then evaluated by Western blot analysis, using an anti-37LRP/67LR polyclonal antibody and an anti-T7 tag monoclonal antibody, in V-293 and LR-293 cell lysates. LR-293 cells expressed both endogenous and transfected 37LRP (37LRP/T7tag), whereas V-293 cells expressed only endogenous 37LRP (Figure 2A).

To verify that transfected 37LRP was correctly processed into the mature form and over-expressed at the cell surface, flow cytometry analysis was performed on V-293 and LR-293 cells with the same polyclonal antibody. LR-293 cells showed increased 67LR surface expression in respect to V-293 cells (Figure 2B).

Finally, 67LR overexpressed on LR-293 cell surface was functionally active; indeed, LR-293 cell adhesion to LM was significantly increased, as compared to V-293 cells, and such an increase was completely abrogated by cell pre-treatment with anti-37LRP/67LR polyclonal antibodies (Figure 2C).

\section{Cell adhesion to LM of 67LR overexpressing cells is inhibited by SB-VS selected compounds}

To identify potential molecules able to inhibit 67LR binding to LM, LR-293 cells were subjected to adhesion experiments on LM-coated wells in the presence of the 46 initial hits, dissolved in DMSO and added at a concentration of $2 \times 10^{-5} \mathrm{M}$; DMSO alone was used as a negative control.

Among the 46 candidates, only five compounds (Table 1) were able to inhibit LR-293 cell adhesion to LM (Figure 3A). Moreover, all these compounds satisfy the druglikeness rules defined by Qikprop (QikProp, version 4.1, Schrödinger, LLC). 

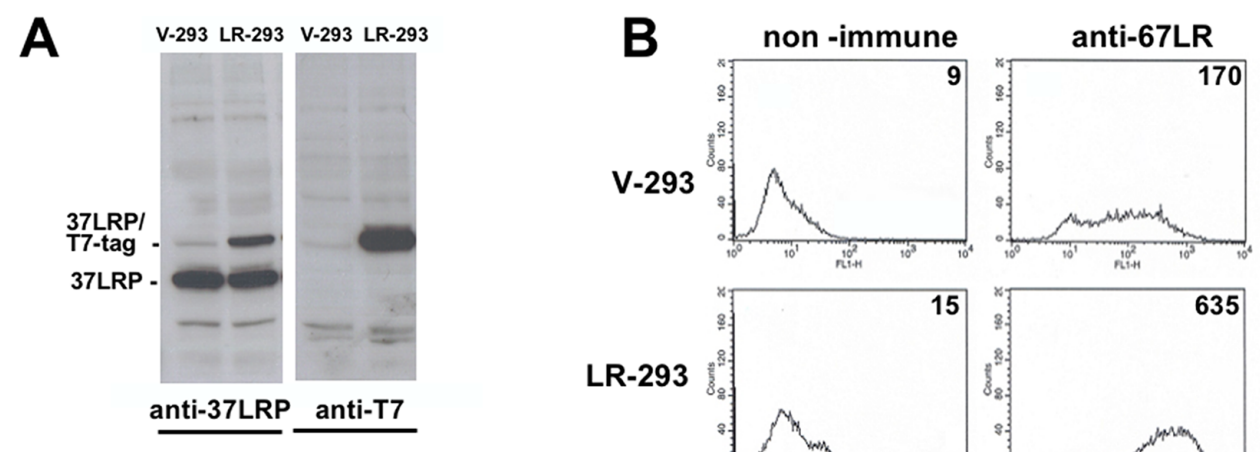

C

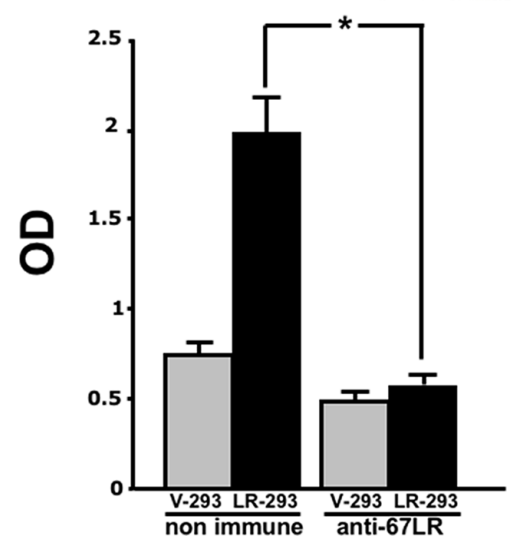

Figure 2: 37LRP cDNA transfection in HEK-293 cells results in cell surface expression of the mature receptor and increased cell adhesion to LM. A. HEK-293 cells were transfected with 37LRP cDNA fused at the C-terminal with a T7 tag and a poly-histidine stretch (37LRP/T7-tag), and named LR-293, or with the empty vector, V-293. Transfected cells were lysed and $50 \mu \mathrm{g}$ of protein was analyzed by Western blot with 37LRP/67LR and T7-tag specific antibodies. B. Flow cytometric analysis of cell surface 67LR expression was evaluated by incubating V-293 and LR-293 cells with a polyclonal anti-67LR antibody or an isotype control. Fluorescence intensity values are reported. C. V-293 ( $\square$ ) and LR-293 (匹) cells were plated on LM-coated wells in the presence of $20 \mu \mathrm{g} / \mathrm{ml}$ non immune immunoglobulins or anti-37LRP/67LR polyclonal antibodies. The attached cells were stained and the absorbance at $540 \mathrm{~nm}$ was measured. The values represent the mean $\pm \mathrm{SD}$ of three experiments performed in triplicate. $\left({ }^{*}\right) p<0.05$, as determined by the Student's $t$ test.

\section{NSC47924 is a specific inhibitor of cell binding to $\mathbf{L M}$}

To verify their specificity, the five active compounds were tested for the ability to inhibit LR-293 cell adhesion to LM, FN and VN. Only one compound selectively inhibited LR-293 cell adhesion to LM. This molecule, NSC47924 [1-((4-methoxyanilino)methyl)-2-naphthol], strongly and specifically decreased cell binding to LM without significantly affect cell adherence to FN and VN (Figure 3B). On the contrary, the other compounds also inhibited cell binding to VN and FN (not shown) and were withdrawn from the study for their lack of specificity.

\section{NSC47924 inhibits cell binding to LM in a dose-dependent manner with a micromolar affinity}

LR-293 cell adhesion to LM was also evaluated in the presence of decreasing concentration of NSC47924, in order to evaluate the dose-dependency of its inhibitory activity. $\mathrm{IC}_{50}$ value was $19.35 \mu \mathrm{M}$, as calculated by nonlinear regression curves using the sigmoidal dose-response analysis of the GraphPad Prism software (Figure 3C). $\mathrm{K}_{i}$ of NSC47924 was $2.45 \mu \mathrm{M}$, as calculated by the Cheng and Prusoff Equation from $\mathrm{EC}_{50}$, using GraphPad Prism [39].

LR-293 cell adhesion to increasing concentrations of LM in the presence of NSC47924 at its $\mathrm{IC}_{50}$ was also evaluated. In the absence of inhibitors, LR-293 cell adhesion to LM showed a $\mathrm{K}_{\mathrm{d}}$ of $14.5 \mathrm{nM}$, similar to that already reported for in vitro 67LR binding to $\mathrm{LM}$ [2 nM; ref. 40]; the addition of NSC47924, at its $\mathrm{IC}_{50}$, resulted in a significant loss of LR-293 cell binding to LM (Figure 3D).

\section{NSC47924 specifically inhibits 67LR-mediated cell adhesion, migration and invasion}

67LR mediates high affinity interaction between cells and LM, thus increasing cell migration and invasiveness in overexpressing cells [21, 22-24, 30]; therefore, it was investigated whether NSC47924 was able to specifically inhibit 67LR-mediated cell adhesion and migration to LM and basement membrane invasion in LR-293 cells, using V-293 cells as a control. 
Table 1: Experimentally Determined \% Cell adhesion Inhibition, XP Docking Scores, and Properties Predicted by QikProp from 46 Screened Compounds

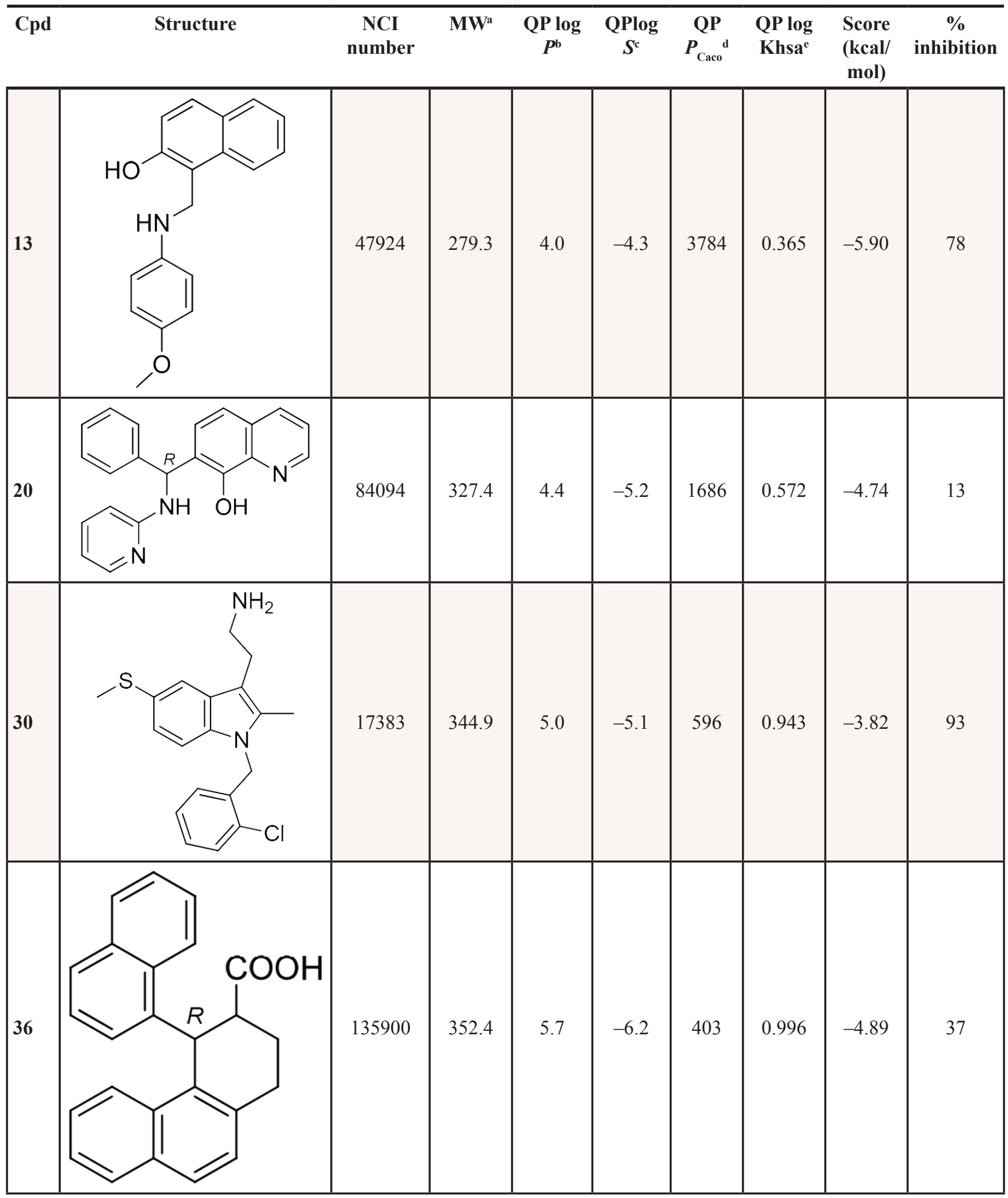

(Continued) 


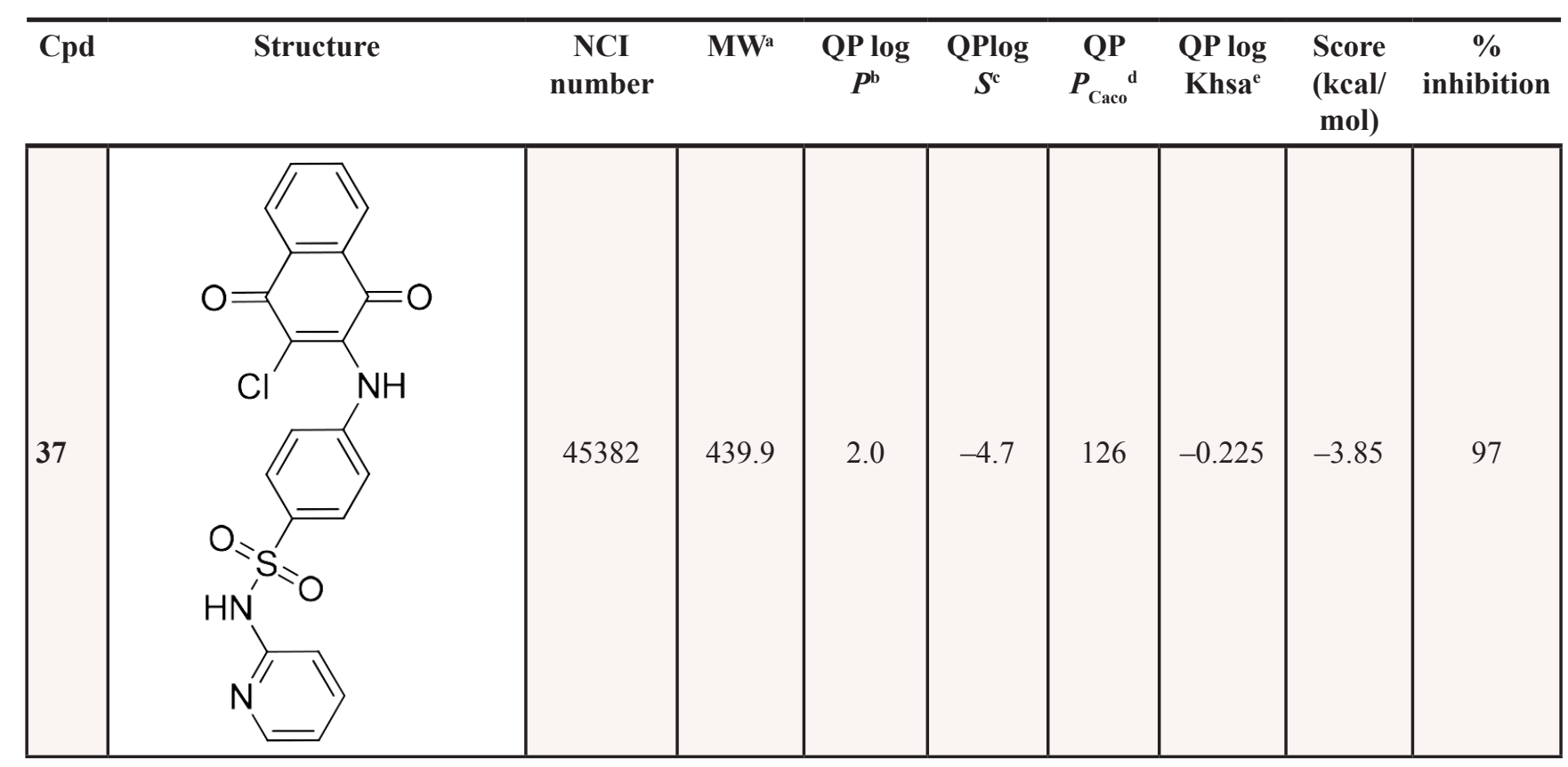

${ }^{a}$ MW, range $95 \%$ of drugs $(130 / 725)$.

${ }^{\mathrm{b}}$ Predicted octanol/water log $P$, range $95 \%$ of drugs $(-2 / 6.5)$.

'Predicted aqueous solubility, $S$, in $\mathrm{mol} / \mathrm{L}$, range $95 \%$ of drugs $(-6.5 / 0.5)$.

${ }^{\mathrm{d}}$ Predicted Caco- 2 cell permeability in $\mathrm{nm} / \mathrm{s}$, range $95 \%$ of drugs ( $<25$ poor, $>500$ great).

ePredicted binding to human serum albumin, range $95 \%$ of drugs $(-1.5 / 1.5)$.

To this aim, in vitro adhesion and migration assays to LM as well as Matrigel invasion assays were performed, in the presence or in the absence of $20 \mu \mathrm{M}$ NSC47924. 67LR overexpressing LR-293 cells showed increased adhesion to LM, migration toward LM and Matrigel invasion, as compared to V-293 cells (Figure 4A, 4B, 4C). NSC47924 significantly inhibited LR-293 cell adhesion/migration to LM and invasion, as compared to vehicle treated cells; no significant effect was observed on V-293 cells (Figure 4A, 4B, 4C). NSC373070, an inactive compound derived from the 46 initial hits (Chart 1 of Supplementary Material), was added as a negative control and was ineffective in inhibiting LR-293 cell adhesion/migration to LM and Matrigel invasion, as expected (Figure 4A, 4B, 4C).

Thus, a novel small molecule specifically inhibiting cell binding to LM and its functional effects in 67LR overexpressing cells was identified by SB-VS.

\section{NSC47924 is a direct inhibitor of 37LRP/LM complex}

To further demonstrate the specificity of 37LRP/67R as a target, the ability of NSC47924 to inhibit the binding to LM of human recombinant soluble 37LRP (r37LRP) was evaluated.

In order to demonstrate r37LRP ability to bind LM, serial dilution of purified His-tagged r37LRP was incubated on wells pre-coated with LM, and binding was detected by anti-His HRP. As a control for binding specificity, r37LRP binding to BSA-coated wells was also evaluated in parallel and the OD readings subtracted. r37LRP specifically bound to LM, albeit with a lower efficiency than 67LR overexpressing cells, showing a $\mathrm{K}_{\mathrm{d}}$ of $1.9 \mu \mathrm{M}$ (Figure $5 \mathrm{~A}$ ), similar to that reported for a truncated form of 37LRP [2.3 $\mu \mathrm{M}$; ref. 41].

Then, NSC47924 ability to inhibit r37LRP binding to LM was evaluated. NSC47924 inhibited r37LRP binding to $\mathrm{LM}$, showing a $\mathrm{IC}_{50}$ of $58.9 \mu \mathrm{M}$ and a $\mathrm{K}_{\mathrm{i}}$ of 35.5 $\mu \mathrm{M}$ (not shown). Thus, NSC47924 is a specific inhibitor of 37LRP/67LR direct binding to LM (Figure 5B).

The precise contact site on LM for 67LR have not been mapped yet. However, it is believed that the interaction involves a specific peptide from the $\beta 1$ chain of laminin (YIGSR) [42]; the binding activity of this synthetic peptide is increased by an amide group at the C-terminal [3]. Moreover, YIGSR is able to displace peptide $\mathrm{G}$ from LM, thus blocking the peptide G-mediated increase in LM degradation [18-19]. For these reasons, we investigated whether NSC47924 was able to compete for r37LRP binding to YIGSR. NSC47924 significantly inhibited r37LRP binding to YIGSR (Figure 5C), leading us to hypothesize that our target sequence, peptide $\mathrm{G}$, could be effectively addressed by NSC47924.

Docking experiments were performed to gain insight into the possible mechanisms of interaction between NSC47924 and peptide G of 37LRP. As shown in Figure 5D, the naphthol ring of the ligand is sandwiched between two $\alpha$-helices ( $\alpha \mathrm{C}$ and $\alpha \mathrm{E}$ ) of 37LRP and held in place by a H-bond 

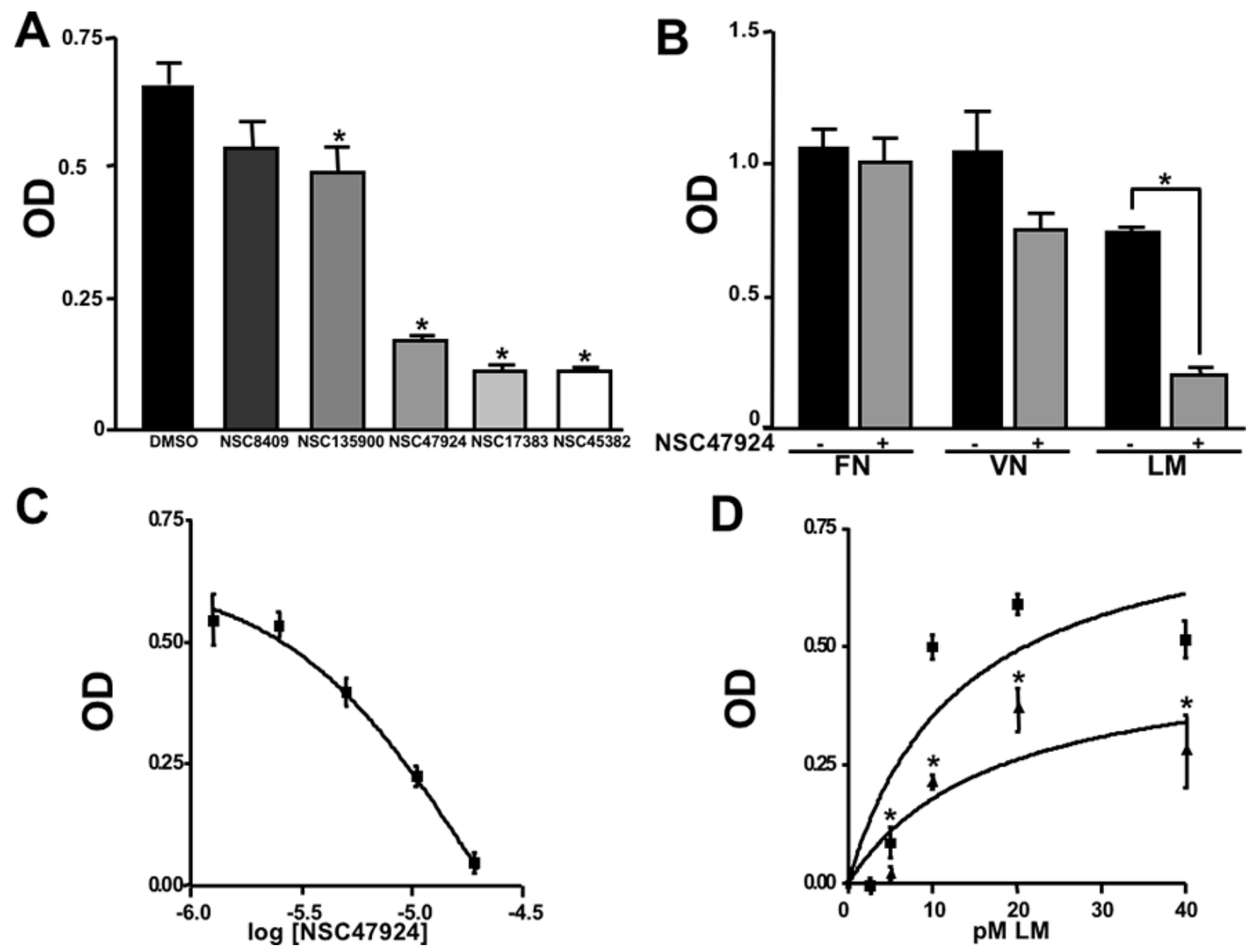

Figure 3: Five top-scoring molecules from SB-VS of a diversity library of small molecules inhibit LR-293 cell adhesion to LM; but, only one compound, NSC47924, shows specificity for LM. A. LR-293 cells were plated in LM-coated wells in the presence of SB-VS selected molecules, at a concentration of $20 \mu \mathrm{M}$, DMSO was used as negative control ( $\mathbf{\square})$. The attached cells were stained and the absorbance at $540 \mathrm{~nm}$ was measured. The values represent the mean $\pm \mathrm{SD}$ of three experiments performed in triplicate. $(*) p<0.05$, as determined by the Student's $t$ test. Among the 46 small molecules tested, only five compounds were able to inhibit LR-293 cell binding to LM and are shown. B. LR-293 cell adhesion to LM, fibronectin (FN) and vitronectin (VN), in the presence of $20 \mu \mathrm{M}$ NSC47924 ( $\square$ ) or DMSO, as a negative control ( $\mathbf{})$. The attached cells were stained and the absorbance at $540 \mathrm{~nm}$ was measured. The values represent the mean \pm SD of three experiments performed in triplicate. $\left({ }^{*}\right) p<0.05$, as determined by the Student's $t$ test. NSC47924, specifically decreased LR293 cell binding to LM, without affecting cell adherence to FN and VN. C. LR-293 cells were plated on LM-coated wells in the presence of decreasing concentrations of NSC47924. The attached cells were stained and the absorbance at $540 \mathrm{~nm}$ was measured. The values represent the mean \pm SD of three experiments performed in triplicate. NSC47924 inhibits LR-293 cell adhesion to LM in a dose dependent manner. D. LR-293 cells were plated for 1 hour on wells coated with increasing concentrations of LM in the presence of NSC47924 ( $\mathbf{\Delta})$, at its IC ${ }_{50}$, or $\operatorname{DMSO}(\mathbf{\square})$, as a vehicle control; attached cells were stained and the absorbance at $540 \mathrm{~nm}$ was measured. Values represent the mean $\pm \mathrm{SD}$ of three experiments carried out in triplicate. The addition of NSC47924, at its $\mathrm{Ic}_{50}$, resulted in a significant loss of LR-293 cell binding to LM.

formed between the hydroxyl group of NSC47924 and the G172 CO backbone. The naphthol moiety also engages a network of hydrophobic contacts with F90, W175, A86, G172, W176, A93, A179 residues. In addition, the pendant p-methoxy phenyl ring makes hydrophobic interactions with the palindromic residues W176 and L173. The aromatic side chain of W176 establishes an aromatic $\pi$-stacking interaction with the $p$-methoxy phenyl ring, contributing to further stabilize the complex. The latter residues have been shown to be critical for specific binding of LM to 37LRP [35]. Close inspection of the NSC47924/37LRP complex also shows that the bulky $p$-metoxy group of the ligand makes van der Waals contacts with the side chain of K17.

\section{Refinement of lead 67LR inhibitor NSC47924}

Hierarchical screening is an efficient strategy that allows an initial broad search over a chemically and pharmacologically diverse set of compounds, followed by a focused search over a much larger database to find molecules related to potential lead compounds. A similarity search over the full NCI database with NSC47924 resulted in 108 
A

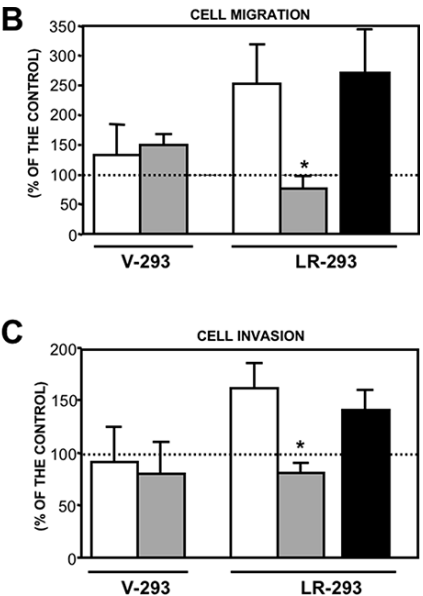

Figure 4: NSC47924 specifically inhibits 67LR-mediated cell adhesion and migration to LM as well as ECM invasion. A. V-293 and LR-293 cells were plated on LM-coated wells in the presence of DMSO (口), as a vehicle control, $20 \mu \mathrm{M} \mathrm{NSC47924} \mathrm{( \square ),} \mathrm{or}$ NSC373070 (- as a negative control. The attached cells were stained and the absorbance at $540 \mathrm{~nm}$ was measured. The values represent the mean \pm SD of three experiments performed in triplicate. $\left(^{*}\right) p<0.05$, as determined by the Student's $t$ test. B. V-293 and LR-293 cells were

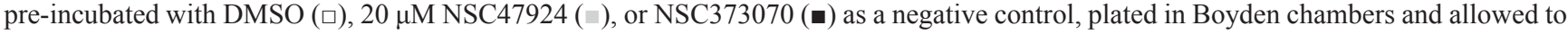
migrate toward $50 \mu \mathrm{g} / \mathrm{ml} \mathrm{LM}$ on filters coated with $10 \mu \mathrm{g} / \mathrm{ml} \mathrm{FN}$. The values are the mean \pm SD of three experiments performed in triplicate. $\left(^{*}\right) p<0.05$, as determined by the Student's $t$ test. C. V-293 and LR-293 cells were preincubated with DMSO ( $\left.\square\right), 20 \mu \mathrm{M}$ NSC47924 ( $\bullet$ ), or NSC373070 (-) as a negative control, plated in Boyden chambers and allowed to invade Matrigel ${ }^{\mathrm{TM}}$. The values are the mean $\pm \mathrm{SD}$ of three experiments performed in triplicate. $\left({ }^{*}\right) p<0.05$, as determined by the Student's $t$ test. NSC47924 inhibited LR-293 cell adhesion and migration to LM as well as Matrigel invasion without exerting any significant effect on vector transfected V-293 cells.

compounds, which we docked to the putative cavity found in close proximity of 37LRP crystal structure and ranked according to predicted binding energy. The top 19 compounds based on a binding energy cutoff of $-7 \mathrm{kcal} / \mathrm{mol}$ were selected for experimental testing (compounds 47-65 in Chart 2 of Supplementary Material: Refinement of lead 67LR inhibitor NSC47924).

The 19 top-ranked compounds identified in the similarity screen were tested at $20 \mu \mathrm{M}$ concentration by in vitro cell adhesion assay to LM. Eight compounds were able to inhibit the adhesion of LR-293 cells to LM (Figure 6A), but only four of them, NSC47923 [1-(4-toluidinomethyl)2-naphthol], NSC48478 [1-((4-chloroanilino)methyl)2-naphthol], NSC48861 [1-((((2-hydroxy-1-naphthyl) methyl)-4-methylanilino)methyl)-2-naphthol] and NSC48869 [1-((((2-hydroxy-1-naphthyl)methyl)anilino) methyl)-2-naphthol] (Table 2) selectively inhibited LR-293 cell binding to LM without exerting a significant effect on cell binding to $\mathrm{FN}$.

To also demonstrate the specificity for 67LR as a target, selected analogs were tested for their ability to inhibit the direct r37LRP binding to LM. NSC47923, NSC48478, NSC48861 and NSC48869 were active to the same extent as NSC47924, by in vitro binding assays (Figure 6C).

Interestingly, all active analogs showed $\mathrm{IC}_{50}$ values lower than $\mathrm{NSC} 47924$, when tested at decreasing concentrations on LR-293 cell adhesion assays (Table 2).

\section{Modes of binding for the top five inhibitors of 67LR}

The five micromolar drug-like inhibitors of 67LR that we have identified, all share a core 1-(anilinomethyl)-2-naphthol scaffold, which is predicted to bind in the deep putative 37LRP binding cleft (Figure 7). The core scaffold, including the H-bonding interaction with the carbonyl backbone of G172, conserves many protein-ligand interactions previously described for NSC47924 (Figure 5D). The naphthol moiety preserves hydrophobic interactions with F90, W175, A86, G172, W176, A93, and A179 residues, whereas the $p$-substituted phenyl ring maintains hydrophobic and aromatic $\pi$-stacking interactions with the palindromic residues W176 and L173. However, the differences of the $p$-substituents account for a large difference in activity. NSC47924 is 9.7-fold and 10.9-fold less active than NSC47923 and NSC48478, respectively. This suggests that the unfavourable steric interactions of the bulky methoxy group of NSC47924 and the $\mathrm{K} 17$ side chain would be removed by the less sterically demanding methyl group (NSC47923) and chlorine atom (NSC48478). The additional 2-naphtol ring in both NSC48861 and NSC48869 establishes favorable hydrophobic contacts with residues G172, L173 and H169, allowing the exploration of a rather lipophilic region of $67 \mathrm{LR}$. One can speculate that specific ligand interactions with this region of the 

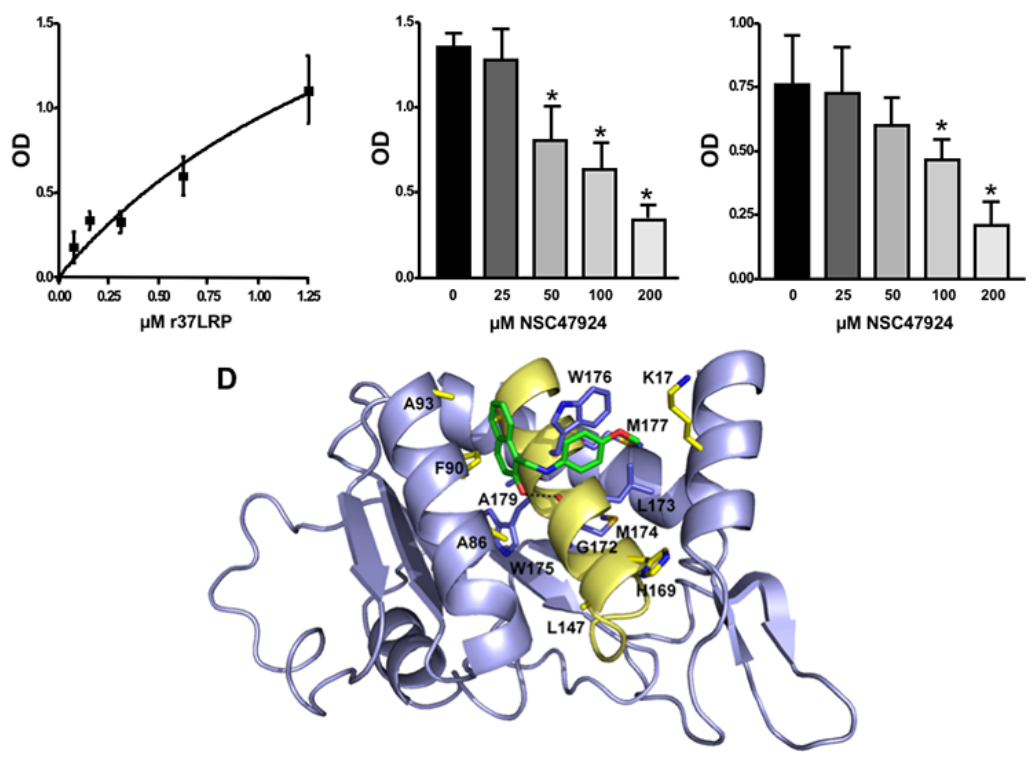

Figure 5: Structural basis of 67LR inhibition by NSC47924. A. Increasing concentrations of purified human His-tagged recombinant 37LRP (r37LRP) were placed for 1 hour at $37^{\circ} \mathrm{C}$ on wells coated with $1 \mu \mathrm{g}$ of LM. Bound r37LRP was revealed by antiHis-HRP and OPD staining; the absorbance at $490 \mathrm{~nm}$ was measured. r37LRP binding to BSA-coated wells was subtracted to obtain specific binding. Values represent the mean $\pm \mathrm{SD}$ of three experiments carried out in triplicate; $\left({ }^{*}, P<0.05\right)$, as determined by the Student's $t$ test. Human r37LRP binds to LM in a dose dependent manner. B. r37LRP was placed for 1 hour at $37^{\circ} \mathrm{C}$ on LM-coated wells in the presence of increasing concentrations of NSC47924 or DMSO ( $\mathbf{a})$, as a vehicle control. Bound r37LRP was revealed by anti-His-HRP and OPD staining; the absorbance at $490 \mathrm{~nm}$ was measured. r37LRP binding to BSA-coated wells was subtracted to obtain specific binding. Values represent the mean $\pm \mathrm{SD}$ of three experiments carried out in triplicate; $(*, P<0.05)$, as determined by the Student's $t$ test. C. r37LRP was placed for 1 hour at $37^{\circ} \mathrm{C}$ on wells coated with $100 \mu \mathrm{g}$ of YIGSR in the presence of increasing concentrations of NSC47924 or DMSO ( $\mathbf{m}$ ), as a vehicle control. Bound r37LRP was revealed by anti-His-HRP and OPD staining; the absorbance at $490 \mathrm{~nm}$ was measured. r37LRP binding to BSA-coated wells was subtracted to obtain specific binding. Values represent the mean \pm SD of three experiments carried out in triplicate; (*, $P<0.05)$, as determined by the Student's $t$ test. D. Predicted binding mode of NSC47924. The most populated and lowest energy pose is shown for NSC47924 docked into the 37LRP crystal structure (slate blue cartoon). NSC47924 is shown in stick, with carbons in green, nitrogens in blue, and oxygen in red. H-bonds interactions are shown with dashed black lines. The protein residues are shown in yellow stick, while the palindromic key residues are displayed in blue sticks. Human recombinant 37LRP binds LM and is inhibited by NSC47924; NSC47924 engages many contacts with residues of 37LRP peptide G.

binding site could increase the inhibitory potency of these two compounds at 67LR.

\section{NSC47923, NSC48478, NSC48861 and NSC48869 inhibit tumor cell invasion}

It has been widely reported that 67LR enhances cancer cell invasion and tumor metastasis by engaging LM and promoting ECM breakdown and the release of LM-derived motility fragments $[18,19]$.

Therefore, we sought to investigate whether selected compounds were able to inhibit the invasion through reconstituted basal membranes of highly invasive human fibrosarcoma HT1080 and human breast cancer MDAMB231 cell lines, constitutively expressing high 67LR levels [30, 43].

All compounds strongly reduced Matrigel invasion, as compared with DMSO-treated cells (Figure 8A). Interestingly, selected compounds were still active at concentrations of $10 \mu \mathrm{M}$ and $5 \mu \mathrm{M}$ (Figure 8B), thus highlighting an increased in vivo activity, as compared to NSC47924 (Figure 4C), most likely due to their lower $\mathrm{IC}_{50}$ (Table 2). NSC210423, an inactive analog derived from the 19 top-ranked compounds identified in the similarity screen (Chart 2 of Supplementary Material), was added as a negative control and was ineffective in inhibiting Matrigel invasion, as expected (Figure 8A, 8B).

Therefore, four newly identified small-molecule inhibitors of 67LR are able to block cancer cell invasion by targeting the direct 67LR binding to LM, at low micromolar concentrations.

\section{DISCUSSION}

Virtual screening (VS) has been successfully adopted as an attractive and complementary alternative to expedite and facilitate new lead compound identification for a specific biological target from large chemical libraries. Typically, VS encompasses a variety of computational techniques to prioritize compounds and it is fast and cost-effective 


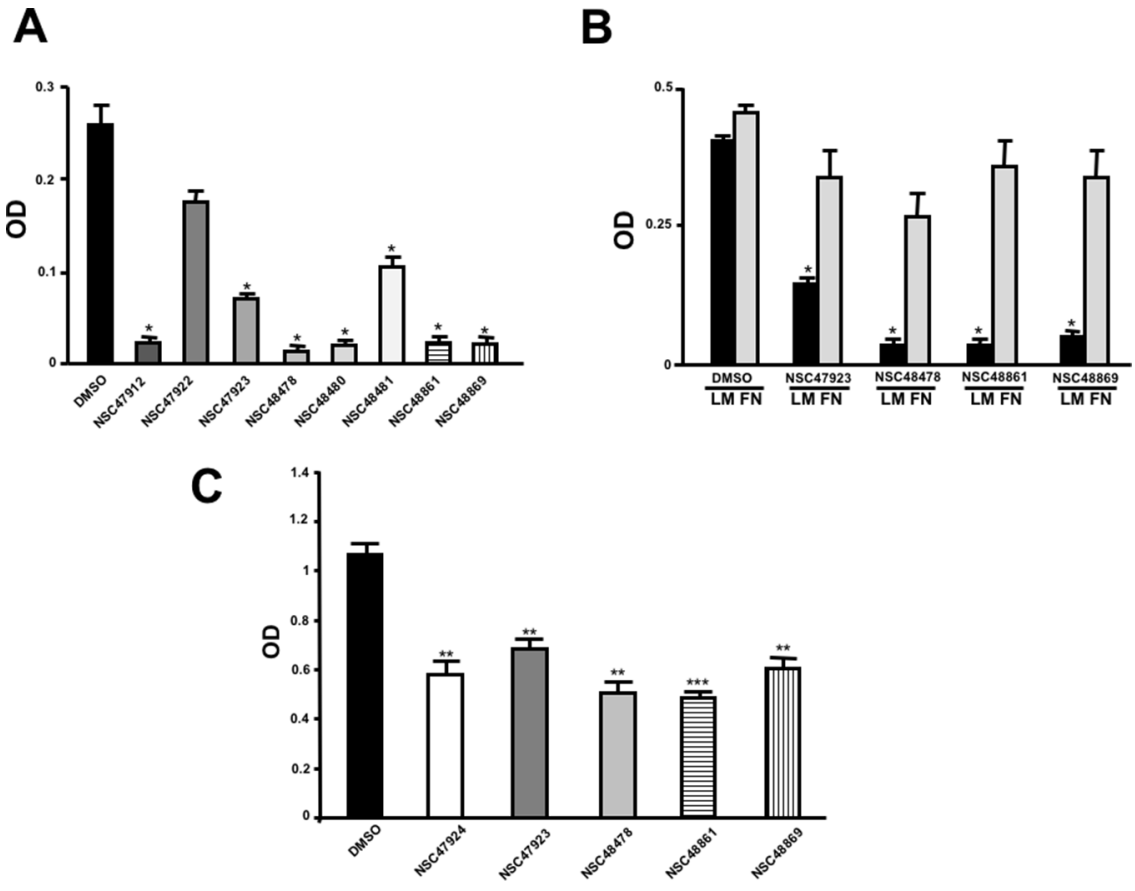

Figure 6: Refinement of lead 67LR inhibitor NSC47924. A. LR-293 cells were plated in LM-coated wells in the presence of the selected molecules, dissolved in DMSO at a concentration of $20 \mu \mathrm{M}$, DMSO was used as negative control ( $\boldsymbol{\bullet})$. The attached cells were stained and the absorbance at $540 \mathrm{~nm}$ was measured. The values represent the mean $\pm \mathrm{SD}$ of three experiments performed in triplicate. $(*) p$ $<0.05$, as determined by the Student's $t$ test. Among the 19 small molecules tested, only eight compounds were able to inhibit LR-293 cell binding to LM and are shown in figure. B. LR-293 cell adhesion to LM ( $\square)$ and FN ( $\square$ ), in the presence of $20 \mu \mathrm{M}$ of inhibitory molecules or DMSO, as a negative control. The attached cells were stained and the absorbance at $540 \mathrm{~nm}$ was measured. The values represent the mean $\pm \mathrm{SD}$ of three experiments performed in triplicate. $\left.{ }^{*}\right) p<0.05$, as determined by the Student's $t$ test. Only four compounds specifically decreased LR-293 cell binding to LM, without affecting cell adherence to FN and are shown in figure. C. r37LRP was placed for 1 hour at $37^{\circ} \mathrm{C}$ on LM-coated wells in the presence of NSC47924 and selected analogs at a concentration of $50 \mu \mathrm{M}$; DMSO ( $\left.\mathbf{}\right)$, was used as a vehicle control. Bound r37LRP was revealed by anti-His-HRP and OPD staining; the absorbance at $490 \mathrm{~nm}$ was measured. r37LRP binding to BSA-coated wells was subtracted to obtain specific binding. Values represent the mean $\pm \mathrm{SD}$ of three experiments carried out in triplicate; (*, $P<0.05 ; * *, P<0.01 ; * * *, P<0.001)$, as determined by the Student's $t$ test.

in comparison to experimental high-throughput screening (HTS), thereby coming to the forefront in the modern drug discovery process [32]. There are two fundamental types of VS applications: structure-based virtual screening (SBVS) and ligand-based virtual screening (LB-VS). SB-VS uses the knowledge of the three-dimensional structure of the target to select candidates most likely to interact with the binding site of the target [33], while LB-VS employs information of the known active compounds as a search query to retrieve the potential actives from large chemical libraries [44]. The main advantages of SB-VS methods compared to LB-VS methods are the structural novelty of the hits discovered (not based on pre-existing, known ligands) and the possibility to model the binding mode of potential ligands within the binding site.

Availability of large number of protein targets in cancer offers an excellent opportunity to carry out VS. In cancer research, successful VS strategies to identify novel hits have been reported by various groups [45]. However, identified hits cannot directly enter into clinical trials, but may serve as starting point for further optimization. Therefore, the VS route of cancer drug discovery provides an excellent opportunity to save time and money, bringing down the cost.

$67 \mathrm{kDa}$ laminin receptor (67LR) overexpression correlates with an enhanced invasive and metastatic potential in many human tumors [22-24] recommending the receptor as a new promising target for cancer drug discovery [25]. This is supported by in vivo studies showing that 67LR downregulation by antisense RNA reduces tumor cell proliferation and tumour formation [46]. Our group recently demonstrated that, upon LM binding, 67LR association with the anti-apoptotic protein PED/PEA-15 activates a signal transduction pathway, leading to cell proliferation and resistance to apoptosis [28]; indeed, siRNA mediated 67LR downregulation reduces cell viability by inducing apoptosis [27].

However, the main function of 67LR is to enhance tumor cell adhesion to the LM of basement membranes and cell migration, two crucial events in the metastasis cascade $[20,21]$. Thus, inhibiting 67LR binding to LM could be a feasible approach to block metastatic cancer cell spread. Recently, several studies have shown that anti37LRP/67LR specific antibodies significantly reduce the 
Table 2: Experimentally Determined $\mathrm{IC}_{50}$ Values and Properties Predicted by QikProp of the four NSC47924 analogs selectively inhibiting LM binding

\begin{tabular}{|c|c|c|c|c|c|c|c|c|}
\hline Cpd & Structure & $\begin{array}{c}\text { NCI } \\
\text { number }\end{array}$ & $\mathbf{M W}^{\mathbf{a}}$ & $\begin{array}{c}\mathrm{QP} \\
\log P^{\mathrm{b}}\end{array}$ & $\begin{array}{c}\mathrm{QP} \\
\log S^{\mathrm{c}}\end{array}$ & 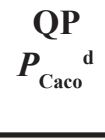 & $\begin{array}{c}\text { QP } \\
\log \\
\text { Khsa }^{\mathrm{e}} \\
\end{array}$ & $\begin{array}{l}\mathrm{IC}_{50} \\
(\mu \mathrm{M})\end{array}$ \\
\hline 50 & & 47923 & 263.3 & 4.0 & -4.4 & 2999 & 0.453 & 1.9 \\
\hline 52 & & 48478 & 283.8 & 4.5 & -5.0 & 3491 & 0.510 & 1.8 \\
\hline 60 & & 48869 & 405.5 & 6.0 & -5.7 & 4484 & 1.032 & 4.0 \\
\hline 61 & & 48861 & 419.5 & 6.3 & -6.5 & 3026 & 1.236 & 3.4 \\
\hline
\end{tabular}

${ }^{\mathrm{a}} \mathrm{MW}$, range $95 \%$ of drugs $(130 / 725)$.

${ }^{b}$ Predicted octanol/water $\log P$, range $95 \%$ of drugs $(-2 / 6.5)$.

'Predicted aqueous solubility, $S$, in $\mathrm{mol} / \mathrm{L}$, range $95 \%$ of drugs $(-6.5 / 0.5)$.

dPredicted Caco- 2 cell permeability in $\mathrm{nm} / \mathrm{s}$, range $95 \%$ of drugs $(<25$ poor, $>500$ great).

ePredicted binding to human serum albumin, range $95 \%$ of drugs $(-1.5 / 1.5)$. 
A

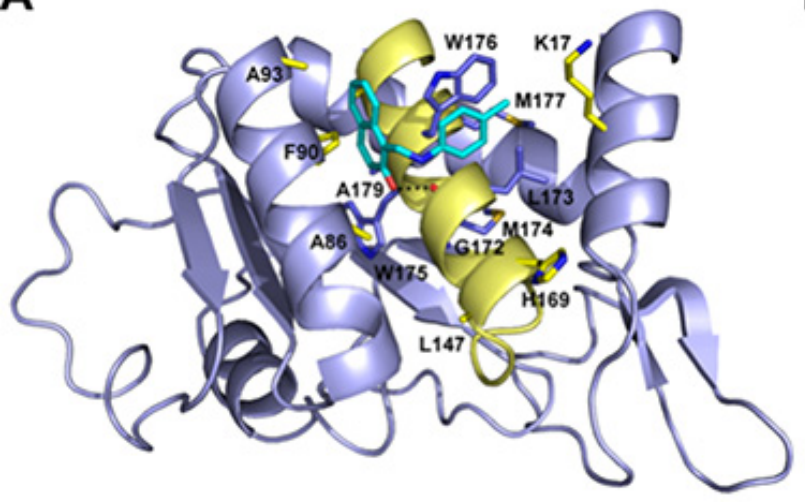

C

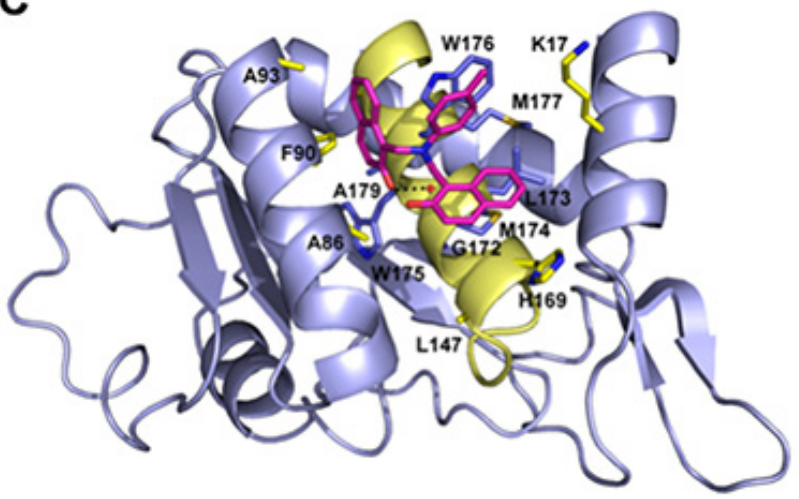

B

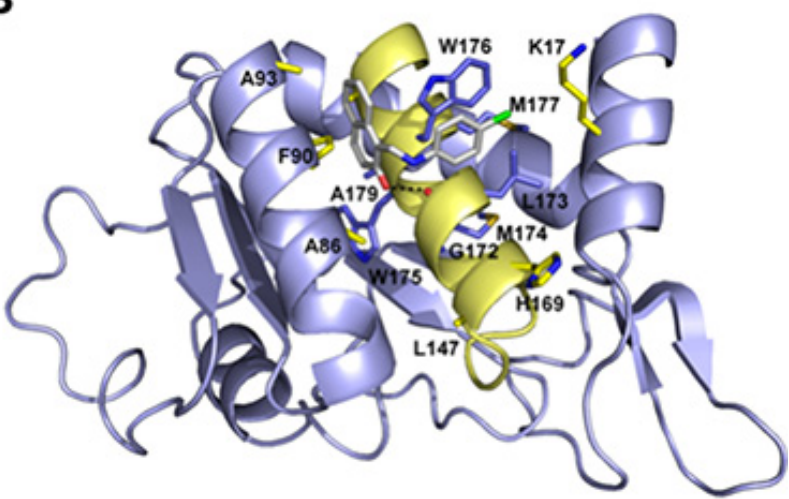

D

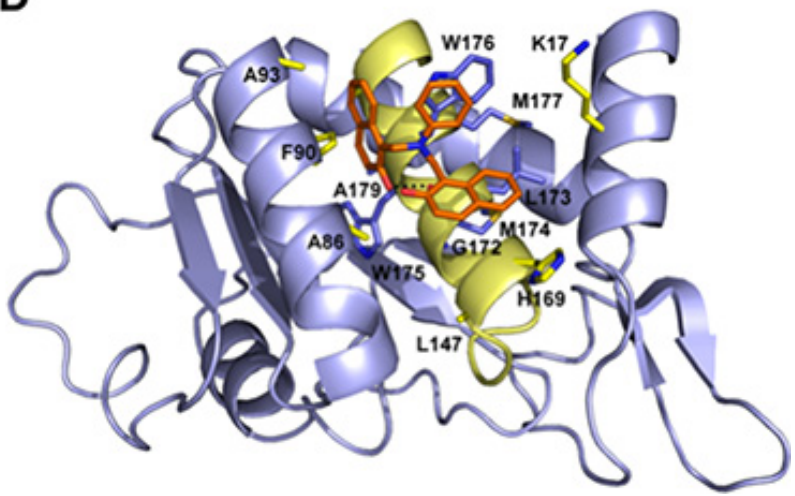

Figure 7: Predicted binding modes to 37LRP for NSC47923 (A. cyan), NSC48861 (B. white), NSC48869 (C. magenta) and NSC48478 (D. orange). Critical 37LRP binding residues are shown (yellow, carbon; red, oxygen; blue, nitrogen), while the palindromic key residues are displayed in blue sticks. H-bonds interactions are shown with dashed black lines.

invasive potential of HT1080 fibrosarcoma, lung, cervical, colon, prostate, breast and oesophageal cancer cells [30, $43,47]$, thus indicating that $67 \mathrm{LR}$ plays a critical role in tumor invasion and metastasis through its interaction with LM. Furthermore, 67LR interaction with LM might also be involved in angiogenesis [48] and recent findings suggest that the same anti-37LRP/67LR antibody is also able to block angiogenesis [29].

Thus, the main goal of our study was to identify small molecules able to inhibit 67LR interaction with LM. In our search for active compounds, we reviewed biological and biochemical data to identify a significant 67LR binding site for LM to target. We focused on the 37LRP-derived "peptide G" sequence (residues 161-180, IPCNNKGAHSVGLMWWMLAR) that binds LM with high affinity $\left(\mathrm{K}_{\mathrm{d}}=51.8 \mathrm{nM}\right)[11,15,17]$, elutes 67LR from LM affinity chromatography columns [17], and mediates many functional effect linked to tumor progression, such as increased cell adhesion and migration to exposed ECM [18], increased tumor cell adhesion to endothelial cells and metastasis formation [15] and release of motility fragments from LM [19].

Interestingly, the mature 67LR originates from a ribosomal protein that acquired the LM binding function during evolution. Indeed, both human 37LRP and the p40 ribosomal protein are encoded by the same gene $[9,10]$.
Sequence conservation of $37 \mathrm{LRP} / \mathrm{p} 40$ genes across species has been demonstrated, with evolution of the C-terminal tail, where is located the LM binding function, convergent with vertebrates [35]. Evolutionary studies also showed that the acquisition of LM-binding capability is linked to the palindromic sequence LMWWML contained within peptide $\mathrm{G}$, which appeared during evolution concomitantly with LM or LM-like molecules. This consistent with the observation that two consecutive tryptophan residues are often associated with protein-protein interaction [49].

The fact that specific amino acid/s could be responsible for the functionality of the complex between 67LR and LM increased the possibility that a small molecule could exert a disrupting effect. Although an antibody and a peptide could also be able to target such interaction, we believe that a small molecule with the same activity would be preferable. Since disruption of LM/67LR interaction should block tumor cell invasion rather than cause cell death, to be an effective treatment, the drug would have to be used chronically in patients suspected to have overt disseminated or residual disease. A successful outcome implies prolonged treatments and thus the need for a drug with oral availability and high index of specificity for cancer cells. Because the library was selected on the basis of Lipinski's rule for drug-like properties [50], and because of the target, which is an interaction that takes place when 

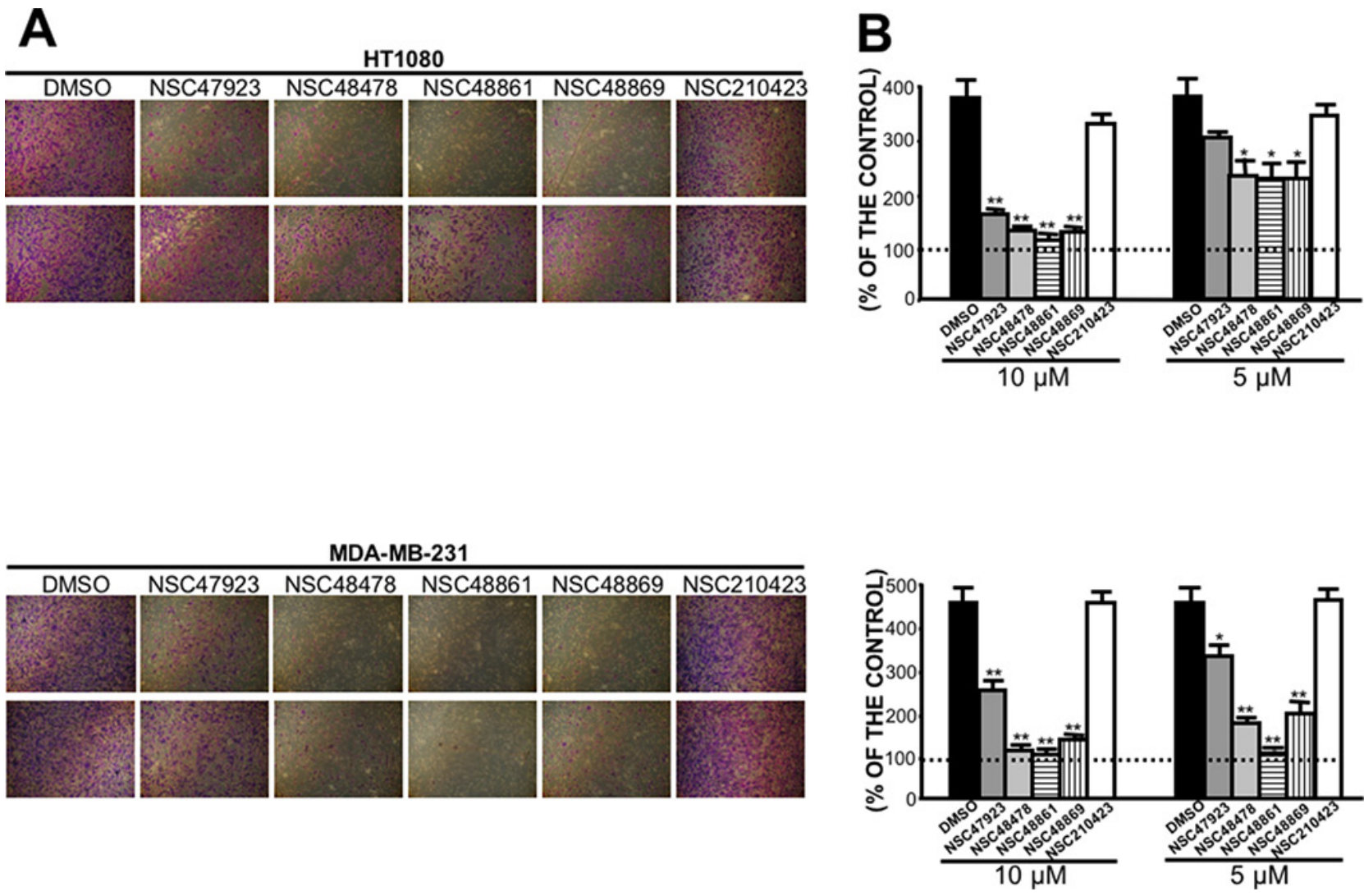

Figure 8: Selected close analogs of NSC47924 block very efficiently cancer cell invasion. A. Highly invasive HT1080 fibrosarcoma cells (upper panel) and MDAMB231 human breast cancer cells (lower panel) were treated with DMSO, with $10 \mu \mathrm{M}$ (first line) and $5 \mu \mathrm{M}$ (second line) of compounds NSC47923, NSC48478, NSC48861, NSC48869 and NSC210423, as a negative control, and allowed to invade Matrigel, using as chemoattractant cell culture medium supplemented with 10\% FBS. Invading cells on the lower side of the membranes were fixed, stained and photographed: a representative image is shown. B. Highly invasive HT1080 fibrosarcoma cells (upper panel) and MDAMB231 human breast cancer cells (lower panel) were treated with DMSO ( $\square$ ), with $10 \mu \mathrm{M}$ and $5 \mu \mathrm{M}$ of compounds

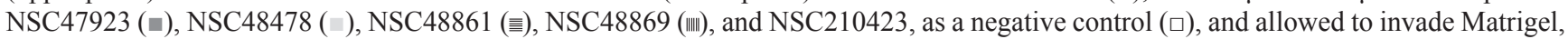
using as chemoattractant cell culture medium supplemented with $10 \%$ FBS. Invading cells on the lower side of the membrane were fixed, stained and counted and the results were expressed as a percentage of invasion in the absence of chemoattractant. The values are the mean \pm SD of three experiments carried out in triplicate; $\left({ }^{*}, P<0.05 ; * * P<0.01\right)$, as determined by the Student's $t$ test. FBS-induced cancer cell invasiveness was significantly reduced by compounds NSC47923, NSC48478, NSC48861, NSC48869, at both concentrations tested.

67LR is over-expressed, a condition of malignant tumors, those two requirement should be satisfied.

The crystal structure of 37LRP reveals that the surface loop of residues 187-205 completely covers peptide $\mathrm{G}$, making it inaccessible. Thus, to expose the palindromic sequence, we truncated the surface loop of 37LRP and intercepted a hydrophobic cavity in close proximity of the palindromic residue W176. This putative cavity was chosen for in silico targeting in a SB-VS approach, which has already been used to successfully identify small molecule inhibitors of urokinase receptor (UPAR) [51], Cdc25B dual specificity phosphatases [52] and frataxin ubiquitination [53].

This approach led to the identification of a small molecule, NSC47924, with 67LR/LM disrupting activity. Since, small molecules have a higher likelihood for off-target effects (based on non-selectivity) in respect to protein-like biologicals [54], we demonstrated that NSC47924 reduced adhesion and migration to LM as well as Matrigel invasion of 67LR-overexpressing cells, without exerting any significant effect in vectortransfected cell, poorly expressing 67LR.

NSC47924 is expected to reduce cancer cell spread, rather than cause acute cancer cell death; however, we cannot exclude that NSC47924 can diffuse through the cell membrane, or be internalized upon 67LR binding, and thus exert also a role on cell proliferation and survival by targeting cytosolic, ribosomal and/or nuclear 37LRP.

Indeed, one of the most important advantages of small molecules, in respect to monoclonal antibodies, is cell membrane permeability. Moreover, the short half-life of small molecules may be of considerable clinical benefit in tailoring personalized target therapies in cancer, as it is emerging in rheumatology [55]. 
Hierarchical screening over the full NCI database with NSC47924, molecular docking studies and cell adhesion experiments identified four NSC47924 related compounds, NSC47923, NSC48478, NSC48861 and NSC48869, that showed increased 67LR inhibition ability, as compared to NSC47924.

In summary, we combined SB-VS experiments with in vitro assays and found five active molecules that were able to selectively disrupt the 67LR/LM activity in a timely and cost-effective fashion. In particular, we have identified a specific inhibitor of cell binding to LM, NSC47924, which is cell-permeable and selectively target 67LR-mediated cell adhesion, migration and invasion as well as four its close analogs (NSC47923, NSC48478, NSC48861 and NSC48869), even more active. This specificity, together with its simple chemical structure, make this compound class suitable for further development of novel therapeutics for the treatment of 67LR-dependent human malignancies.

\section{MATERIALS AND METHODS}

\section{Computational chemistry}

Molecular modeling and graphics manipulations were performed using Maestro (Maestro, version 9.9, Schrödinger, LLC) and Pymol [56] software packages running on a E4 Computer Engineering E1080 workstation provided of a Intel Core i7-930 Quad-Core processor.

\section{Protein preparation}

The X-ray coordinates of the 37LRP fragment (PDB code 3BCH) [31] were extracted from the Protein Data Bank [57]. The structure was then prepared using the Protein Preparation Wizard of the Schrödinger graphical interface Maestro. X-ray water molecules and surface loop domain (residues 187-205) were removed during protein preparation, the last step of which was energy minimization of the entire structure. The minimization was terminated when the root mean square deviation (rmsd) of the heavy atoms in the energy minimized structure relative to the starting (X-ray) coordinates exceeded $0.3 \AA$.

\section{Ligand preparation and filtering}

3D structures of NCI Diversity Set (1, 990 compounds) were extracted by the web site http:// dtp.nci.nih.gov/branches/dscb/repo_open.html/ and prepared using LigPrep's ligand preparation protocol (LigPrep, version 3.1, Schrödinger, LLC). So, about 2, 560 structures including stereoisomers, tautomers, and ionization states were ready to be submitted to the subsequent docking runs.

\section{SB-VS protocol}

The Glide v6.4 (Glide, version 6.4, Schrödinger, LLC) [37] VS application in Schrödinger Small-Molecule Drug Discovery Suite was used to screen the compound library using two levels of docking precision. In the first step, Glide was run in Standard Precision (SP) mode. The $10 \%$ of the top-scoring ligands (188 compounds) were kept and redocked using the Glide Extra Precision (XP) mode, which incorporates a more accurate, finer-grained docking algorithm, designed to eliminate false positives that survive the SP stage. After visual inspection of the top ranked compounds, 46 hits were chosen for biological evaluation. The grid for docking studies was chosen sufficiently large to enclose all residues involved in the palindromic sequence of peptide G (LMWWML) within a cubic box of dimensions $40 \AA \times 40 \AA \times 40 \AA$. The enclosing box was centered on the palindromic sequence setting the bounding box with the sizes of $14 \AA \times 14 \AA \times 14 \AA$. A van der Waals radius scaling factor of 0.80 for atoms with a partial atomic charge (absolute value) less than 0.15 was used in order to soften the potential for nonpolar parts of the receptor. Compounds identified by SB-VS were flexibly docked using the same protein grid prepared for SB-VS protocol. Ten poses were collected for each ligand and ranked according to predicted Glide XP score.

\section{Hierarchical similarity search}

An online search utility provided by the NCI (http://129.43.27.140/ncidb2/) was used to search the entire NCI database for compounds similar to NSC 47924. Two methods were used to judge compound similarity: search on the basis of substructure by SMILES string (http://daylight.com) and/or similarity by Tanimoto coefficient, [58] with a cutoff of 0.85 [59]. From these searches, selected compound structures were docked to the putative LM binding pocket and ranked according to predicted Glide XP score. Compounds with the lowest scoring value were requested and assayed for effect on cell adhesion inhibition.

\section{Chemical inhibitors}

All compounds identified by SB-VS were obtained from the NCI/DTP Open Chemical Repository (http://dtp. cancer.gov), dissolved in dimethyl sulfoxide (DMSO) and stored at $-20^{\circ} \mathrm{C}$, at a concentration of $0.01 \mathrm{M}$.

\section{Epitope tagging of the 37LRP for eukaryotic cell transfection}

The 37LRP cDNA was fused at the carboxy terminus with a sequence coding for both a T7 tag and a 6xHis tag, by a two step procedure. First, the 37LRP coding sequence was PCR amplified from 
plasmid pPLR1.1 [8], kindly provided from Dr. M.E. Sobel, (Bethesda, MD), using oligonucleotides PR11 (GATCCCATTGATGTCCCCAGCCCTTGACGT) and PR12 (GATCCCATGGACCACTCAGTGGTGGCT) as $5^{\prime}$ and $3^{\prime}$ primers, respectively. The product was then cloned in frame into the Nco I site of the pTRcHisB vector (Invitrogen, Carlsbad, CA, USA), upstream the T7-tag and His-tag sequences. Second, the chimeric sequence was PCR amplified using oligonucleotides PR10 (GATCAAGCTTATGTCCGGAGCCCTTGACG) and PR5 (AGCTTCTAGATCAGAGCTCGGATCCTTATCGTC) as $5^{\prime}$ and $3^{\prime}$ primers, respectively. The product was cloned into the Hind III and Xba I sites of pcDNA3 eukaryotic vector (Invitrogen). The resulting plasmid was named pPLR2.5.

\section{Cell cultures and transfections}

The human embryonic kidney cell line HEK-293 (ATCC Certified from LGC Standards, Milan, Italy) was grown in Dulbecco's modified Eagle's medium (DMEM) (GIBCO, Gaithersburg, MD, USA) supplemented with $10 \%$ fetal bovine serum (FBS).

$5 \times 10^{6}$ HEK-293 cells, cultured overnight in 100 $\mathrm{mm}$ tissue culture dishes, were stably transfected with 10 $\mu \mathrm{g}$ of pPLR2.5, or pcDNA3 and $60 \mu \mathrm{l}$ of LipofectAMINE (Invitrogen) for $5 \mathrm{~h}$ at $37^{\circ} \mathrm{C}(5 \% \mathrm{CO} 2)$. Transfected cells, named LR-293 and V-293 respectively, were selected by Geneticin (GIBCO) at $1.5 \mathrm{mg} / \mathrm{ml}$, pooled, and cultured in the presence of $0.5 \mathrm{mg} / \mathrm{ml}$ Geneticin.

67LR highly expressing HT1080 fibrosarcoma [30] and MDAMB231 breast cancer cell lines [43] were grown in DMEM supplemented with 10\% FBS.

\section{Production of recombinant 37LRP and anti-67LR antibodies}

A recombinant polypeptide was made in bacteria for production of anti-37LRP/67LR antibodies, as described [23].

\section{Flow cytometry}

Flow cytometric analysis of cell surface molecules was performed as previously described [59].

\section{Western blot}

Cells were lysed in PBS $(0.08 \mathrm{M} \mathrm{NaCl}, 0.002$ $\mathrm{M} \mathrm{KCl}, 0.0115$ M Na2HPO4, 0.002 M KH2PO4, pH 7.2) containing $1 \%$ Triton $\mathrm{X}-100$, in the presence of a protease inhibitor cocktail containing AEBSF, Aprotinin, Bestatin, E-64, Leupeptin and Pepstatin A (SigmaAldrich, St. Louis, MO, USA) and a phosphatase inhibitor cocktail containing microcystin LR, cantharidin, and bromotetramisole (Sigma-Aldrich). Protein concentration of lysates was determined using a colorimetric assay (Biorad, Richmond, CA, USA). Equal amounts of protein were subjected to SDS-polyacrylamide gel electrophoresis, transferred to poly-vinyl difluoride (PVDF) filters (Millipore, Windsor, MA, USA), then subjected to Western blot with a polyclonal anti-37LRP/67LR antibody or with non-immune immunoglobulins (Igs) (Jackson ImmunoResearch, Suffolk, England), as decribed [23, 60].

\section{Cell adhesion assay}

The adhesion assays were carried out on 96-well flat-bottomed plates (Nunc, Roskilde, Denmark) coated with $1 \mu \mathrm{g}$ of laminin (LM) (Becton Dickinson Biosciences, Franklin Lakes, NJ, USA), fibronectin (FN) (Roche, Indianapolis, USA), vitronectin (VN) (Becton Dickinson Biosciences, Franklin Lakes, NJ, USA) or with $100 \mu \mathrm{l}$ of heat-denatured 1\% Bovine serum albumin (BSA) in PBS, as a negative control, as described [23, 28, 60, 61]. A binding curve and $\mathrm{K}_{\mathrm{d}}$ were generated for compounds using GraphPad Prism software.

\section{Cell migration and invasion assays}

Cell migration assays were performed in Boyden chambers using $8 \mu \mathrm{m}$ pore size polyvinylpyrrolidone (PVPF)-free chemotaxis filters (Wathman Int., Kent, UK), coated with $50 \mu \mathrm{g} / \mathrm{ml}$ collagen, as an adhesion substrate. V-293 and LR-293 cells $\left(2 \times 10^{5}\right)$ were plated in the upper chamber in DMEM 0.1\% BSA containing the selected small molecules or DMSO, as a vehicle control. DMEM $0.1 \%$ BSA alone or containing $50 \mu \mathrm{g} / \mathrm{ml} \mathrm{LM}$ was added in the lower chamber and the cells were allowed to migrate for $4 \mathrm{~h}$ at $37^{\circ} \mathrm{C}, 5 \% \mathrm{CO}_{2}$.

For the invasion assay, filters were coated with

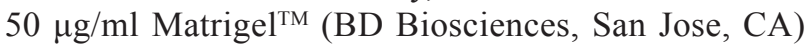
and incubated for $30 \mathrm{~min}$ at $37^{\circ} \mathrm{C}$ for gelling. $2 \times 10^{5}$ cells, plated in the upper chamber in DMEM 0.1\% BSA containing the selected small molecules or DMSO, were allowed to migrate toward DMEM medium supplemented with $10 \% \mathrm{FCS}$, or toward DMEM medium supplemented with $0.1 \% \mathrm{BSA}$, as a control, for $18 \mathrm{~h}$ at $37^{\circ} \mathrm{C}, 5 \% \mathrm{CO}_{2}$.

At the end of both experiments, cells on the lower surface of the filter were fixed in ethanol, stained with hematoxylin, and counted at $200 \times$ magnification (10 random fields/filter). Cell migration and invasion were expressed as a percent increase over the control.

\section{Binding of soluble r37LRP to immobilized LM and YIGSR peptide}

High binding plates with 96 flat-bottomed wells (Corning, Amsterdam, ND) were coated with $1 \mu \mathrm{g} /$ well of LM diluted in PBS, or BSA as a negative control, and incubated at $4^{\circ} \mathrm{C}$ overnight. After a wash in PBS, residual binding sites were blocked for $1 \mathrm{~h}$ at $37^{\circ} \mathrm{C}$ with $200 \mu \mathrm{l}$ of blocking buffer ( $2 \% \mathrm{FCS}, 1 \mathrm{mg} / \mathrm{ml} \mathrm{BSA}$, in PBS). Wells were incubated with increasing concentration of r37LRP 
(diluted in PBS, $1 \mathrm{mg} / \mathrm{ml}$ BSA), which contained a $6 \times$ His-tag, for $1 \mathrm{~h}$ at $37^{\circ} \mathrm{C}$. Each well was washed three times with wash buffer (0.5\% Tween in PBS). Penta-His HRP conjugate (1:500) (Qiagen) was added for $2 \mathrm{~h}$ at room temperature. After washing, substrate solution was added and absorbance was detected at $490 \mathrm{~nm}$ on an ELISA plate reader (Bio-Rad). Binding affinity was determined by subtracting background absorbance (BSA wells). A binding curve and $K_{d}$ were generated for r37LRP using GraphPad Prism software. The $\mathrm{K}_{\mathrm{d}}$ was calculated using a one-site binding hyperbola and the equation $\mathrm{Y}=\mathrm{B}_{\max } \times$ $\mathrm{X} /\left(\mathrm{K}_{\mathrm{d}}+\mathrm{X}\right)$.

For inhibition experiments, wells precoated with $1 \mu \mathrm{g}$ LM or $100 \mu \mathrm{g}$ peptide YIGSR-amide (Polypeptide group, Strasburg) were incubated with $2 \mu \mathrm{g}$ r37LRP, alone or in the presence of different concentrations of NSC47924. Washings, detection and analysis were performed as above described.

\section{CONFLICTS OF INTEREST}

The authors declare no conflicts of interest.

\section{FUNDING}

This work was supported in part by grants from the Compagnia di San Paolo and Polo delle Scienze e delle Tecnologie per la Vita (Progetto F.A.R.O. 2012) as well as Campania Bioscience Grant PON03PE_0060_08.

\section{REFERENCES}

1. Rao NC, Barsky SH, Terranova VP, Liotta LA. Isolation of a tumor cell laminin receptor. Biochem Biophys Res Commun. 1983; 111:804-808.

2. Mecham RP. Receptors for laminin on mammalian cells. FASEB J. 1991; 5:2538-2546.

3. Graf J, Ogle RC, Robey FA, Sasaki M, Martin GR, Yamada Y, Kleinman HK. A pentapeptide from the laminin B1 chain mediates cell adhesion and binds the 67,000 laminin receptor. Biochemistry. 1987; 26:6896-6900.

4. Venticinque L, Jamieson KV, Meruelo D. Interactions between laminin receptor and the cytoskeleton during translation and cell motility. PLoS One. 2011; 6:e15895.

5. Scheiman J, Jamieson KV, Ziello J, Tseng JC, Meruelo D. Extraribosomal functions associated with the $\mathrm{C}$ terminus of the $37 / 67 \mathrm{kDa}$ laminin receptor are required for maintaining cell viability. Cell Death Dis. 2010; 1:e42.

6. Castronovo V, Claysmith AP, Barker KT, Cioce V, Krutzsch HC, Sobel ME. Biosynthesis of the $67 \mathrm{kDa}$ high affinity laminin receptor. Biochem Biophys Res Commun. 1991; 177:177-183.
7. Landowski TH, Dratz EA, Starkey JR. Studies of the structure of the metastasis-associated $67 \mathrm{kDa}$ laminin binding protein: fatty acid acylation and evidence supporting dimerization of the $32 \mathrm{kDa}$ gene product to form the mature protein. Biochemistry. 1995; 34:11276-11287.

8. Rao CN, Castronovo V, Schmitt MC, Wewer UM, Claysmith AP, Liotta LA, Sobel ME. Evidence for a precursor of the high-affinity metastasis-associated murine laminin receptor. Biochemistry. 1989; 28:7476-7486.

9. Auth D, Brawerman G. A 33-kDa polypeptide with homology to the laminin receptor: component of translation machinery. Proc Natl Acad Sci USA. 1992; 89:4368-4372.

10. Sato M, Kinoshita K, Kaneda Y, Saeki Y, Iwamatsu A, Tanaka K. Analysis of nuclear localization of laminin binding protein precursor $\mathrm{p} 40$ (LBP/p40). Biochem Biophys Res Commun. 1996; 229:896-901.

11. Castronovo V, Taraboletti G, Sobel ME. Functional domains of the $67 \mathrm{kDa}$ laminin receptor precursor. J Biol Chem. 1991; 266:20440-20446.

12. Mecham RP, Hinek A, Griffin GL, Senior RM, Liotta LA. The elastin receptor shows structural and functional similarities to the $67-\mathrm{kDa}$ tumor cell laminin receptor. J Biol Chem. 1989; 264:16652-16657.

13. Kazmin DA, Hoyt TR, Taubner L, Teintze M, Starkey JR. Phage display mapping for peptide 11 sensitive sequences binding to laminin-1. J Mol Biol. 2000; 298:431-445.

14. Rieger R, Edenhofer F, Lasmezas CI, Weiss S. The human $37-\mathrm{kDa}$ laminin receptor precursor interacts with the prion protein in eukaryotic cells. Nat Med. 1997; 3:1383-1388.

15. Taraboletti G, Belotti D, Giavazzi R, Sobel ME, Castronovo V. Enhancement of metastatic potential of murine and human melanoma cells by laminin receptor peptide G: attachment of cancer cells to subendothelial matrix as a pathway for hematogenous metastasis. J Natl Cancer Inst. 1993; 85:235-240.

16. Ardini E, Tagliabue E, Magnifico A, Butò S, Castronovo V, Colnaghi MI, Mènard S. Co-regulation and physical association of the $67-\mathrm{kDa}$ monomeric laminin receptor and the a6ß4 integrin. J Biol Chem. 1997; 272:2342-2345.

17. Magnifico A, Tagliabue E, Butò S, Ardini E, Castronovo V, Colnaghi MI, Mènard S. Peptide, G, containing the binding site of the $67 \mathrm{kDa}$ laminin receptor, increases and stabilizes laminin binding to cancer cells. J Biol Chem. 1996; 271:31179-31184.

18. Berno V, Porrini D, Castiglioni F, Campiglio M, Casalini P, Pupa SM, Balsari A, Mènard S, Tagliabue E. The 67 kDa laminin receptor increases tumor aggressiveness by remodeling laminin-1. Endocr Relat Cancer. 2005; 12:393-406.

19. Ardini E, Sporchia B, Pollegioni L, Modugno M, Ghirelli C, Castiglioni F, Tagliabue E, Mènard S. Identification of a novel function for $67-\mathrm{kDa}$ laminin receptor: increase in laminin degradation rate and release of motility fragments. Cancer Res. 2002; 62:1321-1325. 
20. Montuori N, Sobel ME. The 67-kDa laminin receptor and tumor progression. Curr Top Microbiol Immunol. 1996; 213:205-214.

21. Wewer UM, Taraboletti G, Sobel ME, Albrechtsten R, Liotta LA. Role of laminin receptor in tumor cell migration. Cancer Res. 1987; 47:5691-5698.

22. Menard S, Tagliabue E, Colnaghi MI. The $67 \mathrm{kDa}$ laminin receptor as a prognostic factor in human cancer. Breast Cancer Res Treat. 1998; 52:137-145.

23. Montuori N, Selleri C, Risitano AM, Raiola AM, Ragno P, Del Vecchio L, Rotoli B, Rossi G. Expression of the 67-kDa Laminin Receptor in acute myeloid leukemia cells mediates adhesion to laminin and is frequently associated with monocytic differentiation. Clin Cancer Res. 1999; 5:1465-1472.

24. Chen A, Ganor Y, Rahimipour S, Ben-Aroya N, Koch Y, Levite M. The neuropeptides GnRH-II and GnRH-I are produced by human $\mathrm{T}$ cell and trigger laminin receptor gene expression, adhesion, chemotaxis and homing to specific organs. Nat Med. 2002; 8:1421-1426.

25. Scheiman J, Tseng JC, Zheng Y, Meruelo D. Multiple functions of the 37/67-kd laminin receptor make it a suitable target for novel cancer gene therapy. Mol Ther. 2010; 18:63-74.

26. Nelson J, McFerran NV, Pivato G, Chambers E, Doherty C, Steele D, Timson DJ. The $67 \mathrm{kDa}$ laminin receptor: structure, function and role in disease. Biosci Rep. 2008; 28:33-48.

27. Moodley K, Weiss SF. Downregulation of the non-integrin laminin receptor reduces cellular viability by inducing apoptosis in lung and cervical cancer cells. PLoS One. 2013; 8:e57409.

28. Formisano P, Ragno P, Pesapane A, Alfano D, Alberobello AT, Rea VE, Giusto R, Rossi FW, Beguinot F, Rossi G, Montuori N. PED/PEA-15 interacts with the 67 $\mathrm{kD}$ laminin receptor and regulates cell adhesion, migration, proliferation and apoptosis. J Cell Mol Med. 2012; 16:1435-1446.

29. Khusal R, Da Costa Dias B, Moodley K, Penny C, Reusch U, Knackmuss S, Little M, Weiss SF. In vitro inhibition of angiogenesis by antibodies directed against the 37 kDa/67 kDa Laminin Receptor. PLoS One. 2013; 8:e58888.

30. Zuber C, Knackmuss S, Zemora G, Reusch U, Vlasova E, Diehl D, Mick V, Hoffmann K, Nikles D, Frohlich T, Arnold GJ, Brenig B, Wolf E, et al. Invasion of tumorigenic HT1080 cells is impeded by blocking or downregulating the $37-\mathrm{kDa} / 67-\mathrm{kDa}$ laminin receptor. J Mol Biol. 2008; 378:530-539.

31. Jamieson KV, Wu J, Hubbard SR, Meruelo D. Crystal structure of the human laminin receptor precursor. J Biol Chem. 2008; 283:3002-3005.

32. Lavecchia A, Di Giovanni C. Virtual screening strategies in drug discovery: a critical review. Curr Med Chem. 2013; 23:2839-2860.

33. Lyne PD. Structure-based virtual screening: an overview. Drug Discovery Today. 2002; 7:1047-1055.
34. Demianova M, Formosa TG, Ellis SR. Yeast proteins related to the $\mathrm{p} 40 /$ laminin receptor precursor are essential components of the $40 \mathrm{~S}$ ribosomal subunit. J Biol Chem. 1996; 271:11383-11391.

35. Ardini E, Pesole G, Tagliabue E, Magnifico A, Castronovo V, Sobel ME, Colnaghi MI, Menard S. The $67-\mathrm{kDa}$ laminin receptor originated from a ribosomal protein that acquired a dual function during evolution. Mol Biol Evol. 1998; 15:1017-1025.

36. Di Giovanni C, Grottesi A, Lavecchia A. Conformational switch of a flexible loop in human laminin receptor determines laminin-1 interaction. Eur Biophys J. 2012; 41:353-358.

37. Friesner RA, Banks JL, Murphy RB, Halgren TA, Klicic JJ, Mainz DT, Repasky MP, Knoll EH, Shelley M, Perry JK, Shaw DE, Francis P, Shenkin PS. Glide: a new approach for rapid, accurate docking and scoring 1.Method and assessment of docking accuracy. J Med Chem. 2004; 47:1739-1749.

38. Jacobsson M, Gäredal M, Schultz J, Karlén A. Identification of Plasmodium falciparum spermidine synthase active site binders through structure-based virtual screening. J Med Chem. 2008; 51:2777-86.

39. Cheng Y, Prusoff WH. Relationship between the inhibition constant (K1) and the concentration of inhibitor which causes 50 per cent inhibition (I50) of an enzymatic reaction. Biochem Pharmacol. 1973; 22:3099-3108.

40. Menard S, Castronovo V, Tagliabue E, Sobel ME. New insights into the metastasis-associated $67 \mathrm{kD}$ laminin receptor. J Cell Biochem. 1997; 67:155-165.

41. Jamieson KV, Hubbard SR, Meruelo D. Structure-guided identification of a laminin binding site on the laminin receptor precursor. J Mol Biol. 2011; 405:24-32.

42. Massia SP, Rao SS, Hubbell JA. Covalently immobilized laminin peptide Tyr-Ile-Gly-Ser-Arg (YIGSR) supports cell spreading and co-localization of the 67-kilodalton laminin receptor with alpha-actinin and vinculin. J Biol Chem. 1993; 268:8053-8059.

43. Khumalo T, Reusch U, Knackmuss S, Little M, Veale RB, Weiss SF. Adhesion and Invasion of Breast and Oesophageal Cancer Cells Are Impeded by Anti-LRP/ LR-Specific Antibody IgG1-iS18. PLoS One. 2013; 8:e66297.

44. Lavecchia A. Machine-learning approaches in drug discovery: methods and applications. Drug Discov Today. 2015; 20:318-331.

45. Kumar V, Krishna S, Siddiqi MI. Virtual screening strategies: recent advances in the identification and design of anti-cancer agents. Methods. 2015; 71:64-70.

46. Satoh K, Narumi K, Abe T, Sakai T, Kikuchi T, Tanaka M, Shimo-Oka T, Uchida M, Tezuka F, Isemura M, Nukiwa T. Diminution of 37-kDa laminin binding protein expression reduces tumour formation of murine lung cancer cells. Br J Cancer. 1999; 80:1115-1122. 
47. Omar A, Reusch U, Knackmuss S, Little M, Weiss SF. Anti-LRP/LR-specific antibody IgG1-iS18 significantly reduces adhesion and invasion of metastatic lung, cervix, colon and prostate cancer cells. J Mol Biol. 2012; 419:102-109.

48. Tanaka M, Narumi K, Isemura M, Abe M, Sato Y, Abe T, Saijo Y, Nukiwa T, Satoh K. Expression of the 37-kDa laminin binding protein in murine lung tumor cell correlates with tumor angiogenesis. Cancer Lett. 2000; 153:161-168.

49. Macias MJ, Hyvönen M, Baraldi E, Schultz J, Sudol M, Saraste M, Oschkinat H. Structure of the WW domain of a kinase-associated protein complexed with a proline-rich peptide. Nature. 1996; 382:646-649.

50. Lipinski CA, Lombardo F, Dominy BW, Feeney PJ. Experimental and computational approaches to estimate solubility and permeability in drug discovery and development settings. Adv Drug Deliv Rev. 2001; 46:3-26.

51. Rea VEA, Lavecchia A, Di Giovanni C, Rossi FW, Gorrasi A, Pesapane A, De Paulis A, Ragno P, Montuori N. Discovery of new small molecules targeting the vitronectin binding site of the urokinase receptor that block cancer cell invasion. Mol Canc Ther. 2013; 12:1402-1416.

52. Lavecchia A, Di Giovanni C, Pesapane A, Montuori N, Ragno P, Martucci NM, Masullo M, De Vendittis E, Novellino E. Discovery of new inhibitors of Cde25B dual specificity phosphatases by structure-based virtual screening. J Med Chem. 2012; 55:4142-4158.

53. Lavecchia A, Di Giovanni C, Cerchia C, Russo A, Russo G, Novellino E. Discovery of a novel small molecule inhibitor targeting the frataxin/ubiquitin interaction via structure-based virtual screening and bioassays. J Med Chem. 2013; 56:2861-2873.

54. An X, Tiwari AK, Sun Y, Ding PR, Ashby CR Jr, Chen ZS. BCR-ABL tyrosine kinase inhibitors in the treatment of Philadelphia chromosome positive chronic myeloid leukemia: a review. Leuk Res. 2010; 34:1255-1268.

55. Mócsai A1, Kovács, L, Gergely, P. What is the future of targeted therapy in rheumatology: biologics or small molecules? BMC Med. 2014; 12:43.

56. Warren L. DeLano "The PyMOL Molecular Graphics System.” DeLano Scientific LLC, San Carlos, CA, USA. http://www.pymol.org/

57. Berman HM, Westbrook J, Feng Z, Gilliland G, Bhat TN, Weissig H, Shindyalov IN, Bourne PE. The Protein Data Bank. Nucleic Acids Res. 2000; 28:235-242.

58. Willett P. Similarity-based approaches to virtual screening. Biochem Soc Trans. 2003; 31:603-606.

59. Martin YC, Kofron JL, Traphagen LM. Do structurally similar molecules have similar biological activity? J Med Chem. 2002; 45:4350-4358.

60. Montuori N, Müller F, De Riu S, Fenzi G, Sobel ME, Rossi G, Vitale M. Laminin receptors in differentiated thyroid tumors: restricted expression of the 67-kilodalton laminin receptor in follicular carcinoma cells. J Clin Endocrinol Metab. 1999; 84:2086-2092.

61. Selleri C, Ragno P, Ricci P, Visconte V, Scarpato N, Carriero MV, Rotoli B, Rossi G, Montuori N. The metastasis-associated $67-\mathrm{kDa}$ laminin receptor is involved in G-CSF-induced hematopoietic stem cell mobilization. Blood. 2006; 108:2476-2484. 